\title{
1 Effects of temperature on development, reproduction and 2 size of Trichogramma achaeae: implications for biological 3 control
}

\section{Author names and affiliations}

7 Long Chen ${ }^{\mathrm{a}, \mathrm{b}}$, Jesper Givskov Sørensen ${ }^{\mathrm{b}}$, Annie Enkegaard ${ }^{\mathrm{a} *}$

$8{ }^{a}$ Department of Agroecology, Aarhus University, Research Centre Flakkebjerg, Fors $ø$ gsvej 1, 94200 Slagelse, Denmark

$10{ }^{\mathrm{b}}$ Department of Biology, Aarhus University, Ny Munkegade 116, 8000 Aarhus C, Denmark

$11 *$ Corresponding author

\section{Highlights}

13 - The temperature dependent performance of Trichogramma achaeae was characterised

14 - Acclimation significantly influenced fecundity, development and body size

15 - The overall performance was not improved by acclimation

16 - The female fecundity could be a proxy for the overall performance of T. achaeae 


\section{Abstract}

20 The performance of biological control agents (BCAs) in outdoor crops is strongly regulated 21 by ambient temperature. Understanding the thermal biology of BCAs and manipulating their 22 thermal performance could improve biological control efficacy. In this study, the effects of 23 temperature on several life history parameters (longevity, fecundity, development time, wing 24 size) of the recently commercialised egg parasitoid Trichogramma achaeae Nagaraja \& 25 Nagarkatti (Hymenoptera: Trichogrammatidae) was examined. First, parasitoids were reared 26 at $23{ }^{\circ} \mathrm{C}$ and tested in the laboratory at four constant temperatures $\left(15,20,25\right.$ and $\left.30{ }^{\circ} \mathrm{C}\right)$. 27 Results demonstrated that temperature significantly altered all above parameters. Second, 28 developmental acclimation was applied to manipulate the laboratory performance. Parasitoids 29 were allowed to develop at either of the above four temperatures and their performance were 30 compared at $23{ }^{\circ} \mathrm{C}$. Results showed that developmental acclimation had a significant impact 31 on fecundity, development time and wing size but not on female longevity. Our results have 32 implications for improving the performance of $T$. achaeae in mass production and for its 33 application for biological control under different thermal conditions.

35 Key words: parasitoid, quality control, fecundity, longevity, acclimation 


\section{1. Introduction}

38 Increasing concerns of potential hazards to the environment and human health from pesticide

39 use has promoted development of biological control during the past decades (van Lenteren,

40 2012; van Lenteren et al., 2018). For augmentative biological control, which rely on releases

41 of mass produced natural enemies, the quality of the released individuals are of utmost

42 importance, with quality ultimately being defined as the ability to achieve a successful

43 control under field conditions (van Lenteren, 2003). Quality is often approximated by

44 laboratory measures of one or several life history parameters, such as fecundity, sex ratio,

45 longevity, body size or host-searching ability in addition to tolerance to stresses under

46 conditions in mass production (Sørensen et al., 2012; van Lenteren et al., 2003). It is assumed

47 (but rarely verified) that organisms with good performance in one or several of these proxy

48 parameters also perform better under field conditions.

49 The assumption of quality of biological control agents based on simple laboratory parameters

50 can be questioned for two main reasons. Firstly, the control efficacy relies on the

51 performance of living organisms, which is influenced by the ambient biotic and abiotic

52 environment. Most of the organisms used in biological control are ectothermic insects, and

53 their physiology and behaviour strongly rely on ambient temperature. In field application

54 where temperature fluctuates over space and time, the control efficacy varies and might be

55 strongly limited by unfavourable conditions (Pekár and Hubert, 2008; Tullett et al., 2004).

56 Secondly, mass-rearing of insects could lead to undetected deteriorations in field quality.

57 Mass-rearing of biological control agents (BCAs) usually occur at artificial environmental

58 conditions with high constant temperature and, often, artificial diets to maximise generation

59 turnover (Mackauer, 1976). Under these conditions, BCAs could experience potential

60 laboratory adaptation, i.e. inadvertent selection for particular parameters (e.g. decreased

61 development time or high fecundity) at the expense of other traits. If these are used as quality

62 measures, such populations could be perceived as having high laboratory quality, while field

63 performance might be very different (Gariepy et al., 2014). Furthermore, inbreeding and drift

64 lead to decreased genetic variation and inbreeding depression (Sørensen et al., 2012), and

65 would further contribute to quality-associated poor performance in the field (van Lenteren et

66 al., 2003).

67 To improve quality of BCAs intended for application at specific target temperatures, one

68 obvious way is to explore the thermal plasticity or acclimation. Thermal plasticity is the

69 capacity of an organism to express multiple phenotypes in response to different temperatures

70 thus allowing it to cope with stress by physiological and behavioural modifications

71 (Angilletta 2009). Thus, insects with high thermal plasticity would be predicted to have better 
72 performance at fluctuating or unfavourable climatic conditions (Chevin and Hoffmann, 2017).

73 Plastic modifications could potentially induce changes in quality related performance, for

74 example, storing developing parasitoids at low temperatures may result in reduced

75 reproduction and longevity (Colinet and Boivin, 2011). Many studies have suggested that

76 organisms could increase their performance in environments close to their developmental or

77 acclimation temperatures, as compared to organisms acclimated at other temperatures

78 (Wilson and Franklin, 2002; Angilletta, 2009). These studies implied the possibility to

79 acclimate BCAs and further improve their performance at particular temperature regimes in

80 the field.

81 Acclimation has been studied for several natural enemies and some studies have supported 82 that acclimation may increase performance under certain conditions. For example, 83 acclimation alter the survival of insects at extreme temperatures (Chanthy et al., 2012; 84 Hughes et al., 2010). Research on the predatory mite Gaeolaelaps aculeifer Canestrini (Acari: 85 Laelapidae) showed that cold acclimation increased cold and starvation tolerance (Jensen et 86 al., 2017). Similarly, cold reared $\left(15^{\circ} \mathrm{C}\right)$ two-spotted ladybird (Adalia bipunctata Linnaeus 87 (Coleoptera: Coccinellidae)) consumed more aphids at $15^{\circ} \mathrm{C}$ than they did when reared at 20 88 or $25^{\circ} \mathrm{C}$ (Sørensen et al., 2013). The two above studies also pointed to an associated cost of 89 acclimation with reduced performance at opposite temperatures or reduced predation rate or 90 reproduction at certain temperatures. However, acclimation could still benefit the overall 91 performance of BCAs, for instance by allowing establishment of cold acclimated predatory 92 mites at cold areas, particularly when costs are identified and quantified (Hart et al., 2002). 93 For short-lived insects, such as the egg parasitoids Trichogramma spp., the short life span 94 limits the scope for sensing and plastically responding to environmental change, as these 95 have been shown to be time-consuming processes (DeWitt et al., 1998). Therefore, 96 developmental acclimation could potentially improve their biological control efficacy in 97 unfavourable environment.

98 Trichogramma achaeae Nagaraja \& Nagarkatti (Hymenoptera: Trichogrammatidae) is a 99 recently commercialised species mainly used to control tomato leaf miner Tuta absoluta 100 Meyrick (Lepidoptera: Gelechiidae) in tomato (Cabello et al., 2012). Successful biological 101 control requires the knowledge of biology and ecology of a potential agent (Bale et al., 2008).

102 However, little information is available on the thermal performance of this species. In a 103 previous study by Cascone et al. (2015), longevity and fecundity was investigated at three 104 different temperatures, which is inadequate to fully understand the consequences of different 105 temperatures for the performance of this species. In the present study, in order to understand 106 the thermal biology of $T$. achaeae, we tested how different ambient temperatures alter 107 quality-related parameters (longevity, fecundity, development time, wing size) of T. achaeae. 
108 To further explore whether developmental acclimation can potentially improve the

109 performance of $T$. achaeae, we tested how different developmental acclimation temperatures

110 affected the above parameters. We hypothesised that (1) increasing ambient temperature

111 would result in reduced longevity, development time and wing size as well as in increased

112 fecundity up to an optimal temperature; (2) $25{ }^{\circ} \mathrm{C}$ would be optimal as reported for other

113 Trichogramma species (Krechemer et al., 2015); and (3) parasitoids acclimated at their

114 optimal temperature would achieve a higher performance (in terms of fecundity or similar)

115 than parasitoids acclimated at other temperatures.

\section{2. Materials and Methods}

\section{$118 \quad 2.1$ Experimental animals}

119 T. achaeae was obtained from Bioline AgroSciences Ltd, UK. At delivery, T. achaeae was in 120 the pupal stage inside host eggs (species not disclosed by the company) glued onto cardboard 121 pieces. The shipped material was used directly without storage. Eggs of the Mediterranean 122 flour moth (Ephestia kuehniella Zeller, Lepidoptera: Pyralidae) were used as host for $T$. 123 achaeae in rearing and experiments. UV sterilised E. kuehniella eggs were received every 124 second week in bulk in bottles from Koppert B.V., the Netherlands, and stored at $4{ }^{\circ} \mathrm{C}$. 125 Parasitoids were fed with $50 \%$ (v: v) organic honey solution as suggested by Singhamuni et 126 al. (2015).

\section{$127 \quad 2.2$ Laboratory rearing}

128 Parasitoids were reared continuously for a period of 4 months. Received T. achaeae cards $\left(\mathrm{F}_{0}\right)$ 129 were maintained in semi-transparent plastic bottles (approx. $300 \mathrm{ml}$ ) in a climate room at $13023 \pm 1{ }^{\circ} \mathrm{C}$, with a photoperiod of 12: 12 (L: D). Bottles were positioned horizontally in a glass 131 aquarium at the bottom of which was placed a petri dish (diameter: $9 \mathrm{~cm}$ ) with saturated $132 \mathrm{NaCl}$ solution to maintain humidity in between $\mathrm{RH} 70 \pm 10 \%$. Initially, each bottle contained 1331 card with approximately 2,500 parasitised host eggs. Upon emergence, newly emerged 134 parasitoids ( $<24 \mathrm{~h}$ old) were provided with honey solution as food and with fresh $E$. 135 kuehniella eggs glued on 2 cardboard pieces $\left(1.3 * 6.3 \mathrm{~cm} /\right.$ card, approximately 500 eggs $\left./ \mathrm{cm}^{2}\right)$ 136 for oviposition for $24 \mathrm{~h}$. Hereafter, the cards were transferred to new bottles and kept in the 137 rearing aquarium as described above for adult emergence after which the rearing cycle was 138 repeated. The first parasitoids to be used for experimentation (Experiment 1) came from the $139 \mathrm{~F}_{1}$-generation (i.e. after a full generation of rearing in the laboratory) to avoid systematic 140 errors arising from the rearing conditions at the producer (Good, 1993). 


\subsection{Performance at ambient temperature (Experiment 1)}

142 The experiments were conducted in climate chambers at constant temperatures of 15, 20, 25, 143 and $30 \pm 1{ }^{\circ} \mathrm{C}, \mathrm{RH} 70 \pm 10 \%$, photoperiod $12 \mathrm{~L}: 12 \mathrm{D}$. Experiments were divided into 2 parts

144 based on the measurements at different life stages. Longevity and fecundity were measured 145 directly for females of $F_{1}$ and development time and wing size (as a proxy for body size) 146 were measured for the offspring of $F_{1}$. Figure 1 shows the workflow of the experiments.

\section{$147 \quad$ 2.3.1 Experimental 1a: longevity and fecundity}

148 Prior to experimentation, egg cards with unhatched pupae were removed from the rearing 149 bottles and emerged parasitoids were fed with honey and kept in bottles for additional 3 hours 150 to ensure that all females were mated (Mills and Kuhlmann, 2000). For each treatment, 30 151 newly emerged females ( $<24$ h old) were randomly selected and individually maintained in 4 $152 \mathrm{ml}$ glass vials sealed with a piece of cotton. For each vial, an E. kuehniella egg card (0.5* 1.3 $153 \mathrm{~cm}$, approximately $500 \mathrm{eggs} / \mathrm{cm}^{2}$ ) was set-in by tweezer and a fine drop of honey solution 154 added to the bottom. Then all vials were horizontally placed in semi-transparent plastic boxes 155 with a petri dish (diameter: $9 \mathrm{~cm}$ ) of saturated $\mathrm{NaCl}$ solution to maintain humidity. Boxes 156 were separately placed into 4 climate chambers at $15,20,25$ and $30 \pm 1{ }^{\circ} \mathrm{C}$.

157 Longevity was recorded as the length of survival period of females. Recordings were made 158 every $24 \pm 2 \mathrm{~h}$ with individual longevities assigned to the mid-point between two 159 observations. Daily recordings proceeded orderly from replicate 1 to 30 and from low 160 temperature to high temperature to avoid systematic errors. Honey solution drops were 161 checked daily and replenished at need.

162 Fecundity was measured as the number of new parasitoids emerging from E. kuehniella eggs 163 that were parasitised during the first 5 days. At day 5, after the longevity recordings was done, 164 E. kuehniella egg cards with these parasitised eggs were moved to new vials, and females 165 were left in their original vials for continued measurement of longevity. Egg cards originating 166 from the same temperature treatment were returned to this treatment for development of the 167 parasitoids into adults. When emergence had ceased, all vials were placed in a freezer at $16824^{\circ} \mathrm{C}$ to kill and store the parasitoids for later counting of the total number of emerged 169 parasitoids.

\section{$170 \quad$ 2.3.2 Experimental 1b: development time and wing size}

171 Assessment of development time and wing size were made for offspring of $F_{1}$-females at the 172 four different temperature treatments. For each temperature, newly emerged females $(<24 \mathrm{~h}$ 173 old) of $\mathrm{F}_{1}$ were offered 16 fresh E. kuehniella egg cards $(0.5 * 1.3 \mathrm{~cm})$ for 3 hours for 174 parasitisation in a climate-controlled room at $23 \pm 1{ }^{\circ} \mathrm{C}, \mathrm{RH} 70 \pm 10 \%$ and 12 : $12 \mathrm{~L}$ : $\mathrm{D}$. The 
175 cards were subsequently randomly grouped into 4 replicates of 4 cards, transferred into vials,

176 placed in similar boxes as in Experiment 1a and kept in climate chambers at the 4 different

177 temperature treatments for parasitoid development. Egg cards were checked daily (every $24 \pm$

$1782 \mathrm{~h}$ ) for emergence. When new parasitoids started to emerge, the egg cards were daily moved

179 to new vials before the emerged parasitoids were killed and stored at $-24{ }^{\circ} \mathrm{C}$ for later analysis.

180 For each replicate, recordings ended when no emergence had been observed for 2

181 consecutive days. The development time was calculated as a weighted time according to the

182 percentage of emergence at different dates. Sex-ratio was not measured as this is determined

183 at the time of oviposition (Luck et al., 2001).

184 Wing size was measured for a total of 32 killed females per treatment ( 8 females per 185 replicate). Females were randomly selected among the emerged parasitoids with the number 186 collected from each emergence day being proportional to the daily emergence percentage out 187 of the total. The length of the wings was measured from the node along with the connected 188 vein to the edge (Figure 2). Measurements were made by taking photos of each female using 189 a Leica microscope camera and determining wing length using ImageJ version 1.52 190 (Schneider et al., 2012).

$191 \quad 2.4$ Experiment 2: performance after developmental acclimation

192 To investigate the effects of developmental acclimation on longevity, fecundity, development 193 time and wing size of $T$. achaeae, parasitoids were acclimated at four constant temperatures $194\left(15,20,25\right.$ and $\left.30 \pm 1{ }^{\circ} \mathrm{C}\right)$ for the whole developmental period, i.e. from parasitisation to 195 emergence. Hereafter, parasitoids were tested at a constant temperature of $23 \pm 1{ }^{\circ} \mathrm{C}$ (Figure 196 1). Parasitoids used for acclimation at the 4 different temperatures came from generation $\mathrm{F}_{4}$ $197\left(15^{\circ} \mathrm{C}\right), \mathrm{F}_{6}\left(20^{\circ} \mathrm{C}\right)$ and $\mathrm{F}_{7}\left(25\right.$ and $\left.30^{\circ} \mathrm{C}\right)$ of the rearing (Figure 1).

198 For each treatment, newly emerged parasitoids ( $<24 \mathrm{~h}$ old) were taken from the rearing and 199 kept in semi-transparent plastic bottles (approx. $300 \mathrm{ml}$ ), fed with honey solution and 200 provided with 2 fresh E. kuehniella egg cards $\left(6.3 * 1.3 \mathrm{~cm} / \mathrm{card}, 500 \mathrm{eggs} / \mathrm{cm}^{2}\right)$. The bottles 201 were placed in plastic box equipped as described for the rearing procedure (section 2.2.) and 202 placed in a climate chamber at the respective acclimation temperature for parasitisation for 24 203 h. Hereafter, the eggs cards with the now parasitised E. kuehniella eggs were placed in 2 new 204 bottles (one card/bottle) and kept at the same acclimation temperature for development until 205 emergence. Upon the emergence of new parasitoids ( $<24 \mathrm{~h}$ old), egg cards with unhatched 206 pupae were removed and emerged parasitoids fed and kept in bottles at $23{ }^{\circ} \mathrm{C}$ for additionally 2073 hours to ensure that all females were mated.

208 For each acclimation treatment, 30 females were randomly selected into vials (4 $\mathrm{ml})$ to record 209 longevity and fecundity at $23{ }^{\circ} \mathrm{C}$. Another group of parasitoids was given 4 fresh $E$. 
210 kuehniella egg cards $(0.5 * 1.3 \mathrm{~cm})$ for $3 \mathrm{~h}$ for parasitisation at $23{ }^{\circ} \mathrm{C}$. Then the parasitised 211 eggs were maintained at $23{ }^{\circ} \mathrm{C}$ for measurement of development time and wing size. All

212 recordings were made as described for Experiment 1 (section 2.3.1, 2.3.2). Due to low 213 parasitisation of females acclimated at $15{ }^{\circ} \mathrm{C}$, the sample size at this treatment was small.

214 Thus, only a total of 27 females were used to measure wing size at the treatment of $15^{\circ} \mathrm{C}$ 215 compared to 32 females for the other temperature treatments. In addition, only 16 parasitoids 216 per replicate were measured for development time at $15^{\circ} \mathrm{C}$, compared to more than 280 per 217 replicate for the other temperature treatments.

\section{$218 \quad 2.5$ Data analysis}

219 All data analyses were carried out using R (Version 3.6.2) (R Core Team, 2019). Thermal 220 effects on life history parameters were analysed using a general linear model (function $\mathrm{lm}$ ). 221 Firstly, all life history parameters were fitted with a simple linear model followed by Q-Q 222 and residual plots to verify assumptions of normality of residuals and homogeneity of 223 variances. Then second order poly-linear regression was performed when simple linear 224 models did not fit the data well. Finally, one-way ANOVA analysis was used where 225 parametric assumptions were met to explore the changes of temperatures on thermal 226 performance of $T$. achaeae. Model selecting was determined by ANOVA test and Akaike 227 information criterion (AIC) values. The lower temperature thresholds $\left(\mathrm{T}_{0}\right)$ for development 228 was estimated by linear regression of development rate on temperature as described by 229 Davidson (1944).

\section{Results}

\section{$232 \quad 3.1$ Performance at ambient temperature (Experiment 1)}

233 Wing size and several life history characteristics of T. achaeae parasitising E. kuehniella eggs

234 were significantly influenced by temperature. Thus, both longevity, development time and 235 wing size decreased with increasing temperature, while fecundity increased with temperature 236 (for a certain temperature range) (Table 1; Figure 3).

237 The temperature dependency for longevity, development time, wing size and fecundity could 238 be described by a second order polynomial model:

$239 P=a+b \cdot T_{a}+c \cdot T_{a}^{2}$

240 where $P$ is parameter in question, $T_{a}$ is the ambient temperature $\left({ }^{\circ} \mathrm{C}\right)$ and $a, b$ and $c$ are 241 constants. 
242 For longevity, which varied between 7 and 19 days $($ Table 1$)$, the model fitting $\left(\mathrm{F}_{(2,113)}=\right.$ $24350.6, \mathrm{p}<0.001)$ gave the curve in Figure $3 \mathrm{a}$ and the following parameter estimates $( \pm \mathrm{SEM})$ : $244 a: 61.039 \pm 9.386, b:-3.779 \pm 0.873, c: 0.066 \pm 0.019$.

245 The development of immature T. achaeae took from 7 to 34 days (Table 1) and the model 246 fitting $\left(\mathrm{F}_{(2,13)}=960.5, \mathrm{p}<0.001\right)$ yielded the curve in Figure $3 \mathrm{~b}$ and the following parameter 247 estimates $( \pm \mathrm{SEM}): a$ : $128.545 \pm 4.555, b:-8.687 \pm 0.424, c: 0.155 \pm 0.009$. The lower 248 temperature threshold $\left(\mathrm{T}_{0}\right)$ for the juvenile development of $T$. achaeae was estimated as $24911.0{ }^{\circ} \mathrm{C}\left(\right.$ ANOVA, $\left.\mathrm{F}_{(3,12)}=17290, \mathrm{p}<0.001\right)$.

250 For wing size, varying between 195 and $260 \mu \mathrm{m}$ (Table 1), the following parameter estimates $251( \pm$ SEM $)$ were obtained for the fitted model $\left(\mathrm{F}_{(2,125)}=162.7, \mathrm{p}<0.001\right.$; Figure 3c $): a$ : $252432.322 \pm 26.591, b:-15.162 \pm 2.473, c: 0.242 \pm 0.055$.

253 Finally, the fecundity of $T$. achaeae, ranging between 25 and 47 viable offspring per female 254 for the first 5 days of the oviposition period (Table 1), was model fitted $\left(\mathrm{F}_{(2,113)}=24.4\right.$, p < $2550.001)$ to give the curve in Figure $3 \mathrm{~d}$ and the following parameter estimates $( \pm \mathrm{SEM}): a$ : $25692.278 \pm 23.130, b: 11.148 \pm 2.151, c:-0.223 \pm 0.048$.

\section{3.2 Performance after developmental acclimation (Experiment 2)}

258 Developmental acclimation had a significant influence on fecundity, development time and 259 wing size of T. achaeae (Table 2). However, developmental acclimation did not affect female 260 longevity $\left(\mathrm{F}_{(3,114)}=1.7, \mathrm{p}=0.17\right.$, mean \pm SEM: $8.18 \pm 0.33$ days across all temperatures, 261 Table 2).

262 The influence of acclimation temperature on fecundity, development time and wing size 263 could be described by a second order polynomial model:

$264 P=a+b \cdot T_{a c}+c \cdot T_{a c}^{2}$

265 where $P$ is parameter in question, $T_{a c}$ is the acclimation temperature during development $\left({ }^{\circ} \mathrm{C}\right)$ and $a, b$ and $c$ are constants.

267 The fecundity of $T$. achaeae expressed at $23{ }^{\circ} \mathrm{C}$ after developmental acclimation increased 268 with acclimation temperature, varying between 28 and 46 viable offspring per female for the 269 first 5 days of the oviposition period (Table 2$)$. The model fit $\left(\mathrm{F}_{(2,115)}=16.8, \mathrm{p}<0.01\right)$ gave 270 the curve in Figure $4 \mathrm{a}$ and the following parameter estimates $( \pm \mathrm{SEM}): a:-34.304 \pm 23.989, b$ : $271 \quad 5.609 \pm 2.233, c:-0.098 \pm 0.049$.

272 Acclimated immature T. achaeae had a development time at $23{ }^{\circ} \mathrm{C}$ varying between 10 and 27311 days (Table 2). The model fit (Figure $4 \mathrm{~b})\left(\mathrm{F}_{(2,13)}=17.0, \mathrm{p}<0.001\right)$ gave the following 274 parameter estimates $( \pm \mathrm{SEM}): a: 7.254 \pm 0.557, b: 0.287 \pm 0.052, c:-0,006 \pm 0.001$. 
275 Finally, the wing size of female offspring of $T$. achaeae that had undergone developmental 276 acclimation ranged between 211 and $224 \mu \mathrm{m}$ (Table 2). The model fit $\left(\mathrm{F}_{(2,118)}=8.5, \mathrm{p}<\right.$ 277 0.001) gave the curve in Figure $4 \mathrm{c}$ and the following parameter estimates $( \pm$ SEM): $a$ : $278316.373 \pm 24.828, b:-9.052 \pm 2.278, c: 0.192 \pm 0.050$.

\section{4. Discussion}

281 Our characterisation of the temperature-dependency of the performance of T. achaeae is of 282 relevance for mass production and field applications. Extended life span would increase the 283 possibility for BCA establishment and maintenance of control efficacy for longer periods of 284 time. Similarly, larger size is correlated with long life span, and high fecundity and body size 285 directly affects field dispersal and searching ability (Kölliker-Ott et al., 2003; Beukeboom, 286 2018). In mass rearing, size and longevity could be optimised by keeping the rearing 287 temperature low. However, at lower temperatures development time increase significantly 288 which would present difficulties in maximising population turnover.

289 For parasitoids, fecundity directly represents the pest kill rate and links to field success 290 (Coelho et al., 2016). In the present study, fecundity maintained a stable level at a broad 291 temperature range $\left(20\right.$ to $30{ }^{\circ} \mathrm{C}$ ) making $T$. achaeae suitable for use in several geographical 292 regions. However, a clear reduction of fecundity was observed when temperature decreased 293 to $15^{\circ} \mathrm{C}$ which is in line with observation for other Trichogramma species (Haile et al., 2002; 294 Pizzol et al., 2010). The highest realised fecundity was achieved around $25^{\circ} \mathrm{C}$, which was 295 similar to previous studies on other Trichogramma species (Krechemer et al., 2015). Overall, 296 these findings partially supported our hypotheses 1) and 2).

297 Trade-offs were apparent between different temperature dependent characteristics of $T$. 298 achaeae. Benefits from increased longevity and body size at low temperatures were thus 299 offset by increased development time and reduced fecundity. Previous studies have reported 300 that resource requirements for survival might leave less energy for reproduction (Hurd, 2001). 301 Although body size generally has been found positively related to fecundity in insects (Honěk, 302 1993), this size-fecundity relationship is reversed across temperatures. Lower developmental 303 temperature results in enlarged body size, however, lower temperatures are usually associated 304 with reduced fecundity. The results of this study suggests that finding a temperature that 305 balance trade-offs between different parameters is feasible. The data showed that fecundity 306 was likely not constrained by a trade-off with longevity with temperature, as the life span 307 period is almost sufficient for females to parasite and deplete their egg load (Özder and Kara, 308 2010; Scholler and Hassan, 2001). Therefore, compared to the indirect effects on biological 309 control efficacy of development time and body size, the presented data point to fecundity as a 
310 general predictor of overall performance under different temperature regimes. Thus, we

311 suggest that any temperature range in favour of fecundity is recommended for achieving high

312 performance. Based on this study, temperatures around $25^{\circ} \mathrm{C}$ would be a suitable temperature

313 for T. achaeae to perform well.

314 Differing from most studies that have directly tested acclimation effects on insect

315 performance at extreme temperatures, we tested acclimated $T$. achaeae at an intermediate

316 temperature. Therefore, results in this study did not provide information as to whether

317 acclimation might improve thermal tolerance, but has demonstrated that acclimation can alter

318 the performance of T. achaeae. Trichogramma achaeae displayed a strong plastic response in

319 fecundity to acclimation supporting our hypothesis that parasitoids would achieve the highest

320 performance when acclimated at their optimal temperature. The highest fecundity was

321 achieved for parasitoids acclimated at the optimal temperature of $25{ }^{\circ} \mathrm{C}$ and decreased sharply

322 with decreasing acclimation temperature. This can been ascribed to an influence on egg

323 maturation which is known to be greatly limited by low temperature (Steigenga and Fischer,

324 2007; Berger et al., 2008). Development time and body size contradicted the hypothesis that

325 parasitoids would perform well at the optimal temperature, as both development rate and

326 body size increased when acclimation temperature decreased to $15^{\circ} \mathrm{C}$ or increased to $30{ }^{\circ} \mathrm{C}$.

327 However, albeit significant, the changes were relatively small and could, in addition, be

328 partly questioned, as the results might have been affected by the small sample size at $15{ }^{\circ} \mathrm{C}$.

329 Unlike previous studies on T. brassicae (Lessard and Boivin, 2013), we did not find that

330 acclimation at low temperatures increase the longevity of T. achaeae at low temperatures

331 Given parasitoids were from different generations and their quality may have altered during

332 rearing and thus differed between experiments, direct comparison of results from the two

333 experiments cannot be made. However, since the highest fecundity was almost equal in both

334 experiments, it might be assumed that the reproductive capacity of $T$. achaeae was

335 maintained among generations. Given this premise, and given the fact T. achaeae acclimated

336 at $15^{\circ} \mathrm{C}$ (Experiment 2) had a fecundity comparable to that of $23{ }^{\circ} \mathrm{C}$-reared parasitoids tested

337 at $15{ }^{\circ} \mathrm{C}$ (Experiment 1), our study has not supported the notion that cold acclimation will

338 lead to an increased fecundity in cold environments as previously reported for T. achaeae by

339 (Cascone et al., 2015). Since no significant reduction of performance was observed when

340 parasitoids were acclimated at $30{ }^{\circ} \mathrm{C}$, further studies regarding performance at extreme

341 temperatures are needed to establish whether rearing at $30{ }^{\circ} \mathrm{C}$ will result in increased

342 performance at a broad range of temperatures. This could improve rearing turnover and

343 biological control efficacy in the field. 
344 An ideal BCA should be able to maintain a relative high efficacy at a prolonged period under

345 variable environments. This study found that $T$. achaeae will be able to survive and perform

346 well at the temperature range encountered during most field applications. Considering the

347 low fecundity at $15{ }^{\circ} \mathrm{C}$, more parasitoids should be released to achieve the same efficacy

348 compared to parasitoids applied at high temperatures. The possibility for altering

349 performance through thermal acclimation might also have implication in relation to cold

350 storage. Given cold acclimation reduced fecundity, it is not recommended to store T. achaeae

351 in the form of parasitised host eggs at low temperature for a long time.

352 Quality control by periodically monitoring several parameters is recommended to maintain 353 and improve quality of parasitoids and ensure field success. Seeing as fecundity was heavily 354 weighted to the overall performance and was influenced by female proportion, measuring 355 these two parameters are essential to quality control. Considering the differences between 356 laboratory and field conditions, further studies linking laboratory assessment to field 357 performance are required.

\section{Conflict of interest}

359 None of the authors have financial or personal relationships that could cause conflict of 360 interest regarding this manuscript.

\section{Author contribution}

362 Long Chen: methodology, investigation, data curation, formal analysis, writing-original draft. 363 Jesper Givskov Sørensen: conceptualisation, methodology, validation, supervision writing364 review \& editing, funding acquisition. Annie Enkegaard: methodology, validation, 365 supervision, writing-review \& editing, funding acquisition.

\section{Acknowledgement}

367 This work was supported by the Department of Agroecology, Aarhus University; and a grant 368 from Aarhus University Research Foundation to JGS [AUFF-E-2015-FLS-8-72]. The authors 369 would like to express special thanks to Dr. Xiangyu Guo, Centre for Quantitative Genetics 370 and Genomics, Aarhus University, for her assistance on statistical analyses and to Dr. Kim 371 Jensen, Department of Bioscience, Aarhus University, for helpful discussion of the 372 manuscript. 


\section{Figures and Tables}

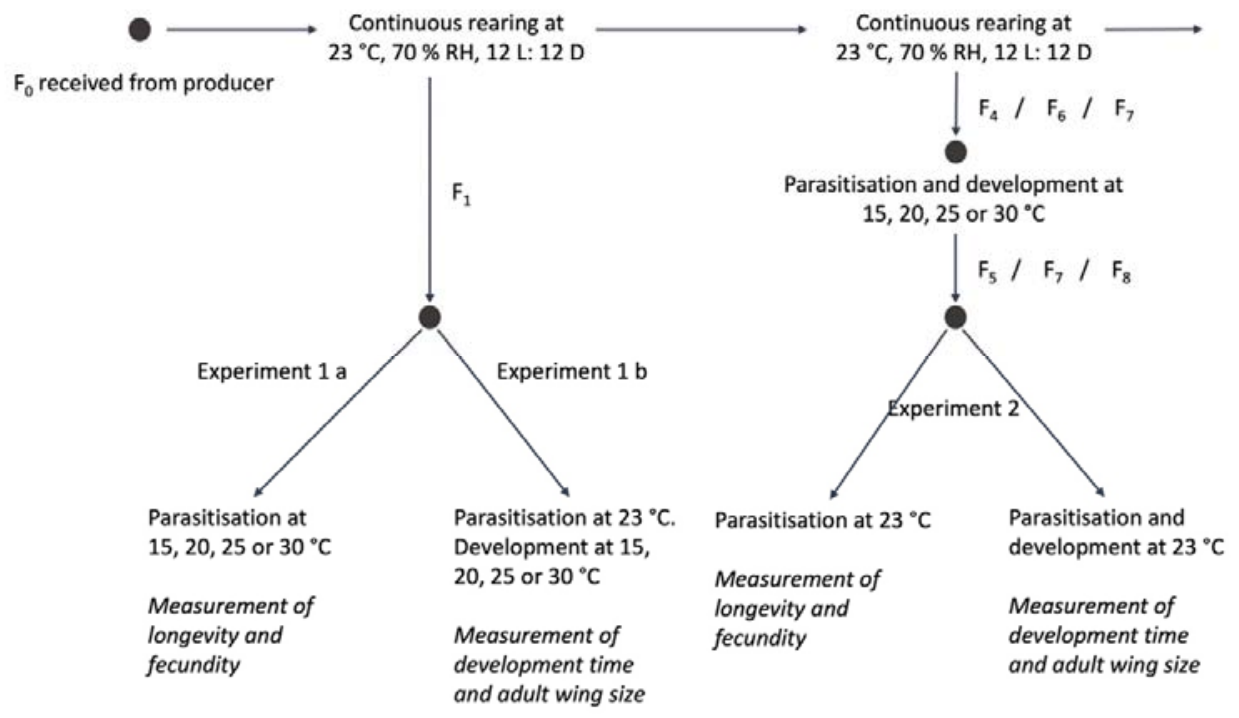

375

376 Figure 1. Experimental workflow. Parasitoids used in Experiment 1 originated from $\mathrm{F}_{1}$. Part

377 of these parasitoids were directly measured for longevity and fecundity. The rest were given

378 E. kuehniella egg for parasitisation and subsequent measurement of development time and 379 wing size. Parasitoids used in Experiment 2 were taken from different generations $\left(\mathrm{F}_{4}, \mathrm{~F}_{6}, \mathrm{~F}_{7}\right)$.

380 Parasitoids were given E. kuehniella egg for parasitisation and subsequent development at 381 either $15,20,25$ or $30{ }^{\circ} \mathrm{C}$. Emerged offspring were then measured at $23{ }^{\circ} \mathrm{C}$ for the same 382 parameters as in Experiment 1 
386 Figure 2. Wing size of Trichogramma achaeae was measured as the length of the dashed line 387 connecting the middle point of the node (point A) to the conjunction (point B) of the edge of 388 the forewing, i.e. approximating the length of the longest vein starting from the node. 
bioRxiv preprint doi: https://doi.org/10.1101/2020.12.14.422618; this version posted December 15, 2020. The copyright holder for this preprint (which was not certified by peer review) is the author/funder, who has granted bioRxiv a license to display the preprint in perpetuity. It is made available under aCC-BY-NC-ND 4.0 International license.
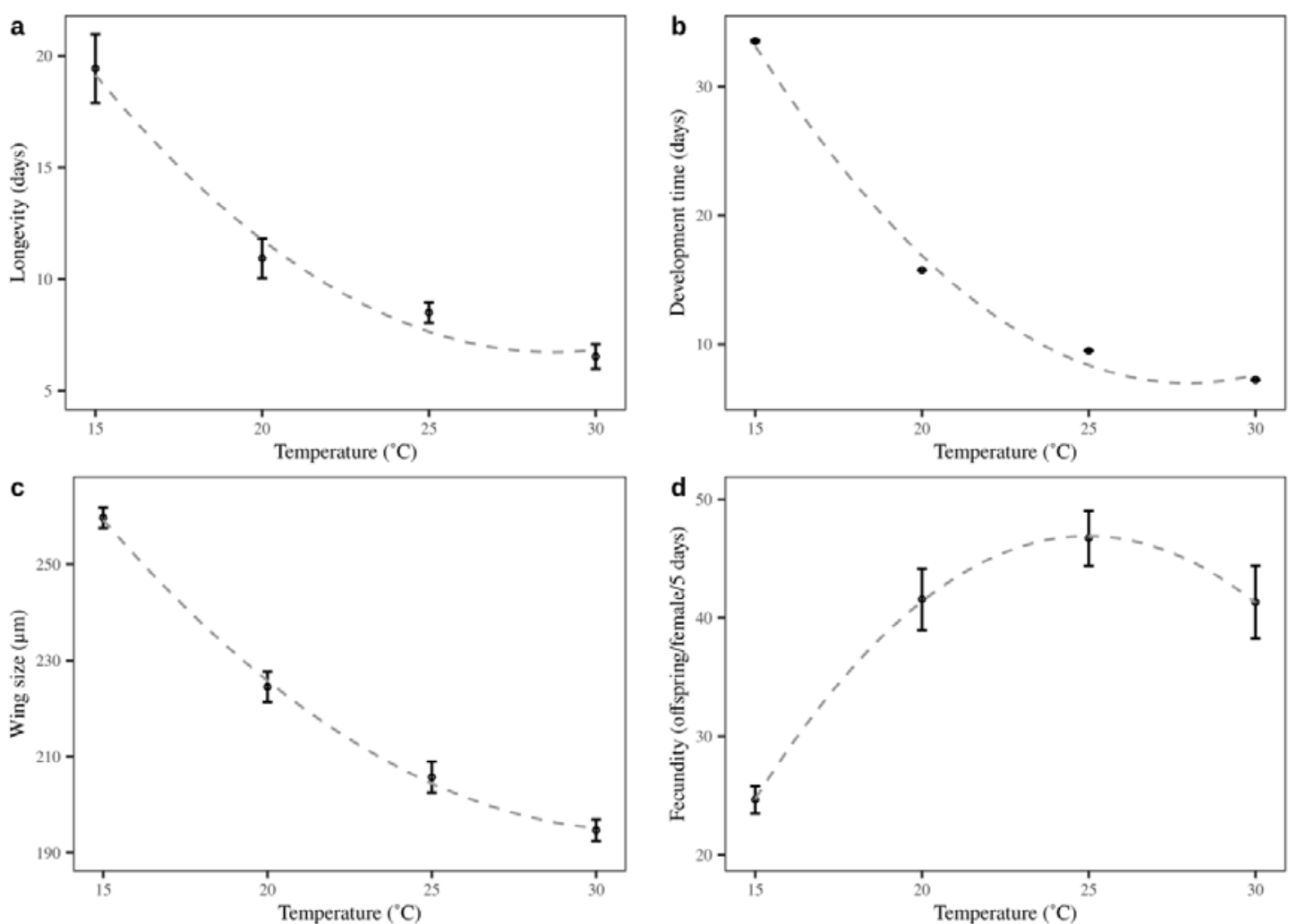

391 Figure 3. Means ( \pm SEM) longevity (a), development time (b), wing size (c) and fecundity (d)

392 of Trichogramma achaeae at four constant temperatures. Dashed lines are predicted values 393 according to model 1 

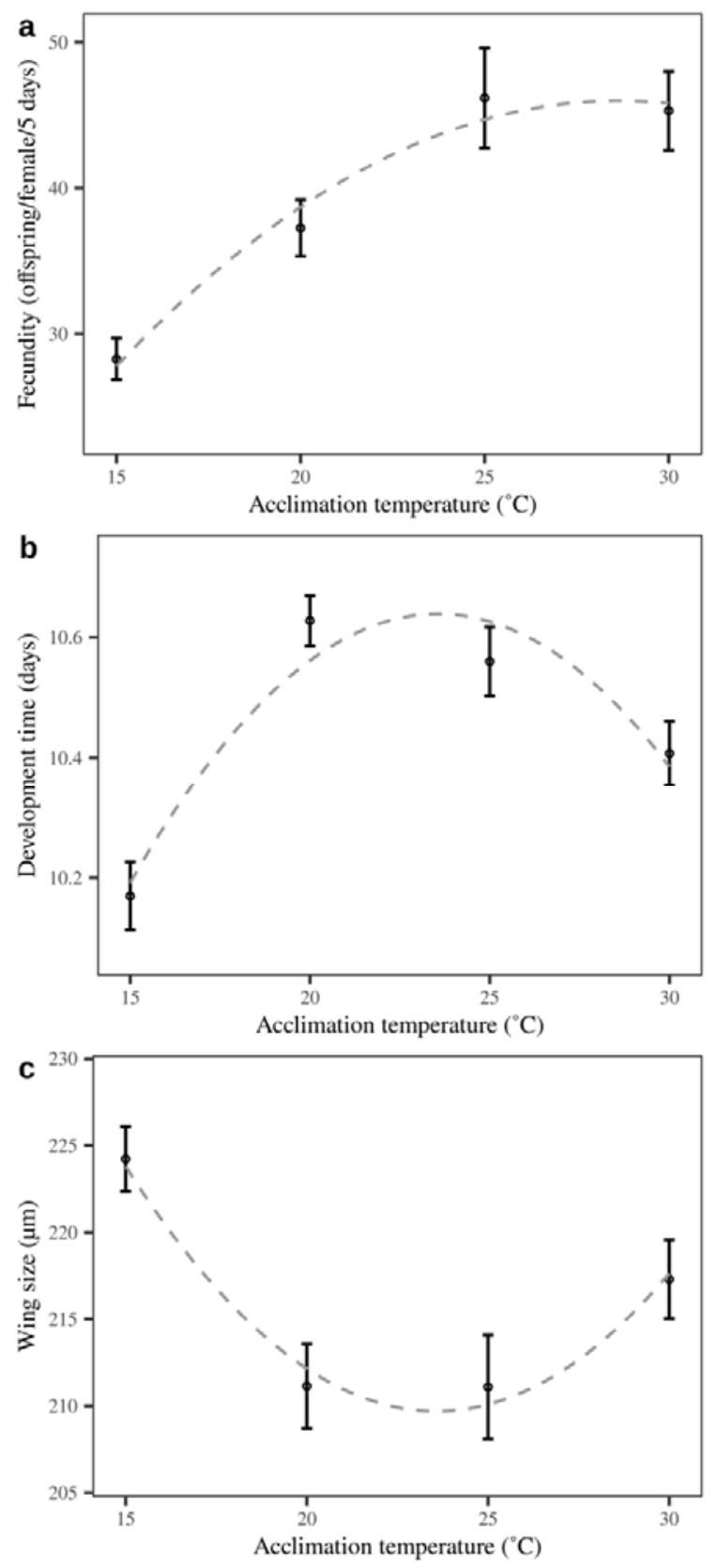

396 Figure 4. Means ( \pm SEM) of three life history parameters, fecundity (a), development time (b) 397 and wing size (c) of Trichogramma achaeae tested at $23{ }^{\circ} \mathrm{C}$ after developmental acclimation 398 at four constant temperatures. Dashed lines are predicted values according to model 2 
bioRxiv preprint doi: https://doi org/10.1101/2020.12 14.422618; this version posted December 15,2020 . The copyright holder for this preprint (which was not certified by peer review) is the author/funder, who has granted bioRxiv a license to display the preprint in perpetuity. It is made available under aCC-BY-NC-ND 4.0 International license.

400 Table 1. Life history parameters and wing size (mean \pm SEM) of Trichogramma achaeae at 4 401 constant temperatures

\begin{tabular}{|c|c|c|c|c|}
\hline Parameters & $15^{\circ} \mathrm{C}$ & $20^{\circ} \mathrm{C}$ & $25^{\circ} \mathrm{C}$ & $30^{\circ} \mathrm{C}$ \\
\hline Longevity (days) & $19.43 \pm 1.54$ & $10.93 \pm 0.88$ & $8.50 \pm 0.46$ & $6.54 \pm 0.55$ \\
\hline Fecundity ${ }^{1}$ & $24.66 \pm 1.16$ & $41.57 \pm 2.59$ & $46.72 \pm 2.33$ & $41.32 \pm 3.09$ \\
\hline Development time (days) & $33.54 \pm 0.06$ & $15.76 \pm 0.03$ & $9.51 \pm 0.04$ & $7.25 \pm 0.03$ \\
\hline Wing size $(\mu \mathrm{m})$ & $259.75 \pm 2.15$ & $224.53 \pm 3.16$ & $205.75 \pm 3.22$ & $194.72 \pm 2.25$ \\
\hline
\end{tabular}

$402{ }^{1}$ Fecundity was measured as the number of emerged parasitoids from Ephestia kuehniella eggs parasitised by

403 newly emerged females during the first 5 days of their oviposition period

404

405

406 
407 Table 2. Life history parameters and wing size (mean \pm SEM) at $23{ }^{\circ} \mathrm{C}$ for offspring of 408 Trichogramma achaeae developmentally acclimated at 4 constant temperatures.

\begin{tabular}{|c|c|c|c|c|}
\hline Parameters & $15^{\circ} \mathrm{C}$ & $20^{\circ} \mathrm{C}$ & $25^{\circ} \mathrm{C}$ & $30{ }^{\circ} \mathrm{C}$ \\
\hline Longevity (days) & $8.93 \pm 0.58$ & $7.20 \pm 0.48$ & $8.84 \pm 0.87$ & $7.74 \pm 0.64$ \\
\hline Fecundity ${ }^{1,2}$ & $28.27 \pm 1.42$ & $37.27 \pm 1.94$ & $46.17 \pm 3.44$ & $45.31 \pm 2.70$ \\
\hline Development time (days) & $10.17 \pm 0.06^{3}$ & $10.63 \pm 0.04$ & $10.56 \pm 0.06$ & $10.41 \pm 0.05$ \\
\hline Wing size $(\mu \mathrm{m})$ & $224.23 \pm 1.87^{3}$ & $211.14 \pm 2.43$ & $211.09 \pm 2.99$ & $217.29 \pm 2.27$ \\
\hline
\end{tabular}

$409{ }^{1}$ Fecundity was measured as the number of emerged parasitoids from Ephestia kuehniella eggs parasitised by

410 newly emerged females during the first 5 days of their oviposition period

$411{ }^{2}$ Offspring numbers might include some offspring from the second generation due to delayed counting caused

412 by a corona-related shutdown of Aarhus University

$413{ }^{3}$ Small sample size due to low parasitisation or emergence rate of females after acclimated at this temperature 
415

416

417

418

419

420

421

422

423

424

425

426

427

428

429

430

431

432

433

434

435

436

437

438

439

440

441

442

443

444

445

446

447

448

449

450

451

452

453

454

455

456

457

\section{References}

Angilletta Jr., M.J., 2009. Thermal adaptation: a theoretical and empirical synthesis. Oxford University Press. https://doi.org/10.1093/acprof:oso/9780198570875.001.1

Bale, J.S., van Lenteren, J.C., Bigler, F., 2008. Biological control and sustainable food production. Philos. Trans. R. Soc. B Biol. Sci. 363, 761-776. https://doi.org/10.1098/rstb.2007.2182

Berger, D., Walters, R., Gotthard, K., 2008. What limits insect fecundity? Body size- and temperature-dependent egg maturation and oviposition in a butterfly. Funct. Ecol. 22, 523-529. https://doi.org/10.1111/j.1365-2435.2008.01392.x

Beukeboom, L.W., 2018. Size matters in insects - an introduction. Entomol. Exp. Appl. 166, 2-3. https://doi.org/10.1111/eea.12646

Cabello, T., Gámez, M., Varga, Z., Garay, J., Carreño, R., Gallego, J.R., Fernández, F.J., 2012. Selection of Trichogramma spp. (Hym.: Trichogrammatidae) for the biological control of Tuta absoluta (Lep.: Gelechiidae) in greenhouses by an entomo-ecological simulation model. IOBC-WPRS Bull. 80, 171-176.

Cascone, P., Carpenito, S., Slotsbo, S., Iodice, L., Sørensen, J.G., Holmstrup, M., Guerrieri, E., 2015. Improving the efficiency of Trichogramma achaeae to control Tuta absoluta. BioControl 60, 761-771. https://doi.org/10.1007/s10526-015-9684-1

Chanthy, P., Martin, R.J., Gunning, R. V., Andrew, N.R., 2012. The effects of thermal acclimation on lethal temperatures and critical thermal limits in the green vegetable bug, Nezara viridula (L.) (Hemiptera: Pentatomidae). Front. Physiol. 3, 1-8. https://doi.org/10.3389/fphys.2012.00465

Chevin, L.-M., Hoffmann, A.A., 2017. Evolution of phenotypic plasticity in extreme environments. Philos. Trans. R. Soc. B Biol. Sci. 372, 20160138. https://doi.org/10.1098/rstb.2016.0138

Coelho, A., Rugman-Jones, P.F., Reigada, C., Stouthamer, R., Parra, J.R.P., 2016. Laboratory performance predicts the success of field releases in inbred lines of the egg parasitoid Trichogramma pretiosum (Hymenoptera: Trichogrammatidae). PLoS One 11, 1-16. https://doi.org/10.1371/journal.pone.0146153

Colinet, H., Boivin, G., 2011. Insect parasitoids cold storage: A comprehensive review of factors of variability and consequences. Biol. Control 58, 83-95. https://doi.org/10.1016/j.biocontrol.2011.04.014

Davidson, J., 1944. On the relationship between temperature and rate of development of insects at constant temperatures. J. Anim. Ecol. 13, 26. https://doi.org/10.2307/1326

DeWitt, T.J., Sih, A., Wilson, D.S., 1998. Costs and limits of phenotypic plasticity. Trends Ecol. Evol. 13, 77-81. https://doi.org/10.1016/S0169-5347(97)01274-3

Gariepy, V., Boivin, G., Brodeur, J., 2014. Why two species of parasitoids showed promise in the laboratory but failed to control the soybean aphid under field conditions. Biol. Control 80, 1-7. https://doi.org/10.1016/j.biocontrol.2014.09.006

Good, D.S., 1993. Evolution of behaviours in Drosophila melanogaster in high temperatures: Genetic and environmental effects. J. Insect Physiol. 39, 537-544. https://doi.org/10.1016/0022-1910(93)90034-O

Haile, A.T., Hassan, S.A., Ogol, C.K.P.O., Baumgärtner, J., Sithanantham, S., Monje, J.C., 
458

459

460

461

462

463

464

465

466

467

468

469

470

471

472

473

474

475

476

477

478

479

480

481

482

483

484

485

486

487

488

489

490

491

492

493

494

495

496

497

498

499

500

501

Zebitz, C.P.W., 2002. Temperature-dependent development of four egg parasitoid Trichogramma species (Hymenoptera: Trichogrammatidae). Biocontrol Sci. Technol. 12, 555-567. https://doi.org/10.1080/0958315021000016225

Hart, A.J., Bale, J.S., Tullett, A.G., Worland, M.R., Walters, K.F.A., 2002. Effects of temperature on the establishment potential of the predatory mite Amblyseius californicus McGregor (Acari: Phytoseiidae) in the UK. J. Insect Physiol. 48, 593-599. https://doi.org/10.1016/S0022-1910(02)00087-2

Honěk, A., 1993. Intraspecific variation in body size and fecundity in insects: a general relationship. Oikos 66, 483-492. https://doi.org/10.2307/3544943

Hughes, G.E., Alford, L., Sterk, G., Bale, J.S., 2010. Thermal activity thresholds of the predatory mirid Nesidiocoris tenuis: Implications for its efficacy as a biological control agent. BioControl 55, 493-501. https://doi.org/10.1007/s10526-010-9267-0

Hurd, H., 2001. Host fecundity reduction: A strategy for damage limitation? Trends Parasitol. 17, 363-368. https://doi.org/10.1016/S1471-4922(01)01927-4

Jensen, K., Kristensen, T.N., Overgaard, J., Toft, S., Sørensen, J.G., Holmstrup, M., 2017. Cold acclimation reduces predation rate and reproduction but increases cold- and starvation tolerance in the predatory mite Gaeolaelaps aculeifer Canestrini. Biol. Control 114, 150-157. https://doi.org/10.1016/j.biocontrol.2017.08.013

Kölliker-Ott, U.M., Blows, M.W., Hoffmann, A.A., 2003. Are wing size, wing shape and asymmetry related to field fitness of Trichogramma egg parasitoids? Oikos 100, 563573. https://doi.org/10.1034/j.1600-0706.2003.12063.x

Krechemer, F.S., Foerster, L.A., 2015. Temperature effects on the development and reproduction of three Trichogramma (Hymenoptera: Trichogrammatidae) species reared on Trichoplusia ni (Lepidoptera: Noctuidae) Eggs. J. Insect Sci. 15, 90. https://doi.org/10.1093/jisesa/iev072

Lessard, E., Boivin, G., 2013. Effect of low temperature on emergence, fecundity, longevity and host-feeding by Trichogramma brassicae. BioControl 58, 319-329. https://doi.org/10.1007/s10526-012-9493-8

Luck, R.F., Janssen, J.A.M., Pinto, J.D., Oatman, E.R., 2001. Precise sex allocation, local mate competition, and sex ratio shifts in the parasitoid wasp Trichogramma pretiosum. Behav. Ecol. Sociobiol. 49, 311-321. https://doi.org/10.1007/s002650000294

Mackauer, M., 1976. Genetic problems in the production of biological control agents. Annu. Rev. Entomol. 21, 369-385. https://doi.org/10.1146/annurev.en.21.010176.002101

Mills, N.J., Kuhlmann, U., 2000. The relationship between egg load and fecundity among Trichogramma parasitoids. Ecol. Entomol. 25, 315-324. https://doi.org/10.1046/j.13652311.2000.00260.x

Özder, N., Kara, G., 2010. Comparative biology and life tables of Trichogramma cacoeciae, T. brassicae and T. evanescens (Hymenoptera: Trichogrammatidae) with Ephestia kuehniella and Cadra cautella (Lepidoptera: Pyralidae) as hosts at three constant temperatures. Biocontrol Sci. Technol. 20, 245-255. https://doi.org/10.1080/09583150903497880

Pekár, S., Hubert, J., 2008. Assessing biological control of Acarus siro by Cheyletus malaccensis under laboratory conditions: Effect of temperatures and prey density. J. Stored Prod. Res. 44, 335-340. https://doi.org/10.1016/j.jspr.2008.02.011 
502 Pizzol, J., Pintureau, B., Khoualdia, O., Desneux, N., 2010. Temperature-dependent

503

504

505

506

507

508

509

510

511

512

513

514

515

516

517

518

519

520

521

522

523

524

525

526

527

528

529

530

531

532

533

534

535

536

537

538

539 differences in biological traits between two strains of Trichogramma cacoeciae (Hymenoptera: Trichogrammatidae). J. Pest Sci. 83, 447-452. https://doi.org/10.1007/s10340-010-0327-0

R Core Team, 2019. R: A language and environment for statistical computing. R Foundation for Statistical Computing, Vienna, Austria. URL https://www.R-project.org/

Schneider, C.A., Rasband, W.S., Eliceiri, K.W., 2012. NIH Image to ImageJ: 25 years of image analysis. Nat. Methods 9, 671-675. https://doi.org/10.1038/nmeth.2089

Scholler, M., Hassan, S.A., 2001. Comparative biology and life tables of Trichogramma evanescens and T. cacoeciae with Ephestia elutella as host at four constant temperatures. Entomol. Exp. Appl. 98, 35-40. https://doi.org/10.1046/j.1570-7458.2001.00754.X

Singhamuni, S.A.A., Hemachandra, K.S., Sirisena, U.G.A.I., 2015. Potential for mass rearing of the egg parasitoids, Trichogramma chilonis and Tricogramma achaeae (Hymenoptera: Trichogrammatidae) on Corcyra cephalonica eggs. Trop. Agric. Res. 27, 1-12.

Sørensen, C.H., Toft, S., Kristensen, T.N., 2013. Cold-acclimation increases the predatory efficiency of the aphidophagous coccinellid Adalia bipunctata. Biol. Control 65, 87-94. https://doi.org/10.1016/j.biocontrol.2012.09.016

Sørensen, J.G., Addison, M.F., Terblanche, J.S., 2012. Mass-rearing of insects for pest management: Challenges, synergies and advances from evolutionary physiology. Crop Prot. 38, 87-94. https://doi.org/10.1016/j.cropro.2012.03.023

Steigenga, M.J., Fischer, K., 2007. Ovarian dynamics, egg size, and egg number in relation to temperature and mating status in a butterfly. Entomol. Exp. Appl. 125, 195-203. https://doi.org/10.1111/j.1570-7458.2007.00610.x

Tullett, A.G., Hart, A.J., Worland, M.R., Bale, J.S., 2004. Assessing the effects of low temperature on the establishment potential in Britain of the non-native biological control agent Eretmocerus eremicus. Physiol. Entomol. 29, 363-371. https://doi.org/10.1111/j.0307-6962.2004.00398.x

van Lenteren, J.C., 2012. The state of commercial augmentative biological control: Plenty of natural enemies, but a frustrating lack of uptake. BioControl 57, 1-20. https://doi.org/10.1007/s10526-011-9395-1

van Lenteren, J.C., 2003. Need for quality control of mass-produced biological control agents, in: van Lentern, J.C. (Ed.), Quality Control and Production of Biological Control Agents: Theory and Testing Procedures. CABI Publishing, Wallingford, pp. 1-18.

van Lenteren, J.C., Bolckmans, K., Köhl, J., Ravensberg, W.J., Urbaneja, A., 2018. Biological control using invertebrates and microorganisms: plenty of new opportunities. BioControl 63, 39-59. https://doi.org/10.1007/s10526-017-9801-4

van Lenteren, J.C., Hale, A., Klapwijk, J.N., van Schelt, J., Steinberg, S., 2003. Guidelines for quality control of commercially produced natural enemies., in: van Lenteren, J.C. (Ed.), Quality Control and Production of Biological Control Agents: Theory and Testing Procedures. CABI Publishing, Wallingford, pp. 265-303. https://doi.org/10.1079/9780851996882.0265

Wilson, R.S., Franklin, C.E., 2002. Testing the beneficial acclimation hypothesis. Trends Ecol. Evol. 17, 66-70. https://doi.org/10.1016/S0169-5347(01)02384-9 